\title{
Surface wave dispersion and crustal structure in Antarctica and the Surrounding Oceans
}

\author{
Robert L. Kovach - Frank Press (*)
}

Ricevuto il 26 maggio 1961

\section{INTRODUCTION.}

During the last decade surface wave dispersion data has provided a great amount of valuable information on crustal structure in widely diversified areas of the earth. However, because of the inherent simplicity in using dispersion data caution must be used in any analysis of crustal structure. In a recent paper, hereafter referred to as paper 1, which appeared in the Geophysical Journal, Evison, Ingham, Orr and Le Fort (1960) presented trans-Antarctic Love and Rayleigh wave dispersion data recorded at the Antarctic IGY stations of Hallett, Scott Base, and Mirny. By comparison with dispersion curves for oversimplified crustal models a crustal thickness of $10 \mathrm{~km}$ was indicated for the South Indian Ocean and a thickness of $35 \mathrm{~km}$ for Eastern Antarctica. Now that digital computer programs exist for computation of dispersion for complicated structures it was decided to reexamine the observed data in the light of new calculations and our current knowledge of the structure of the earth's crust and mantle.

\section{DATA AND DISCUSSION.}

Figure 1 shows the epicenters, and seismograph stations which we shall discuss. Table 1 contains the pertinent information on origin times, epicenters, and great circle distances. The details of the seismographs at the stations have been stated in paper 1 and are not reproduced here.

(*) Contribution No. 1034, Division of Geological Sciences, California Institute of Tecnology. 
Let us now focus our attention on the shock of 9 Sept. 57 and examine one of the conclusions made in paper 1 . Figure 2 shows the observed Love wave dispersion for this shock recorded at Hallet Station. Also

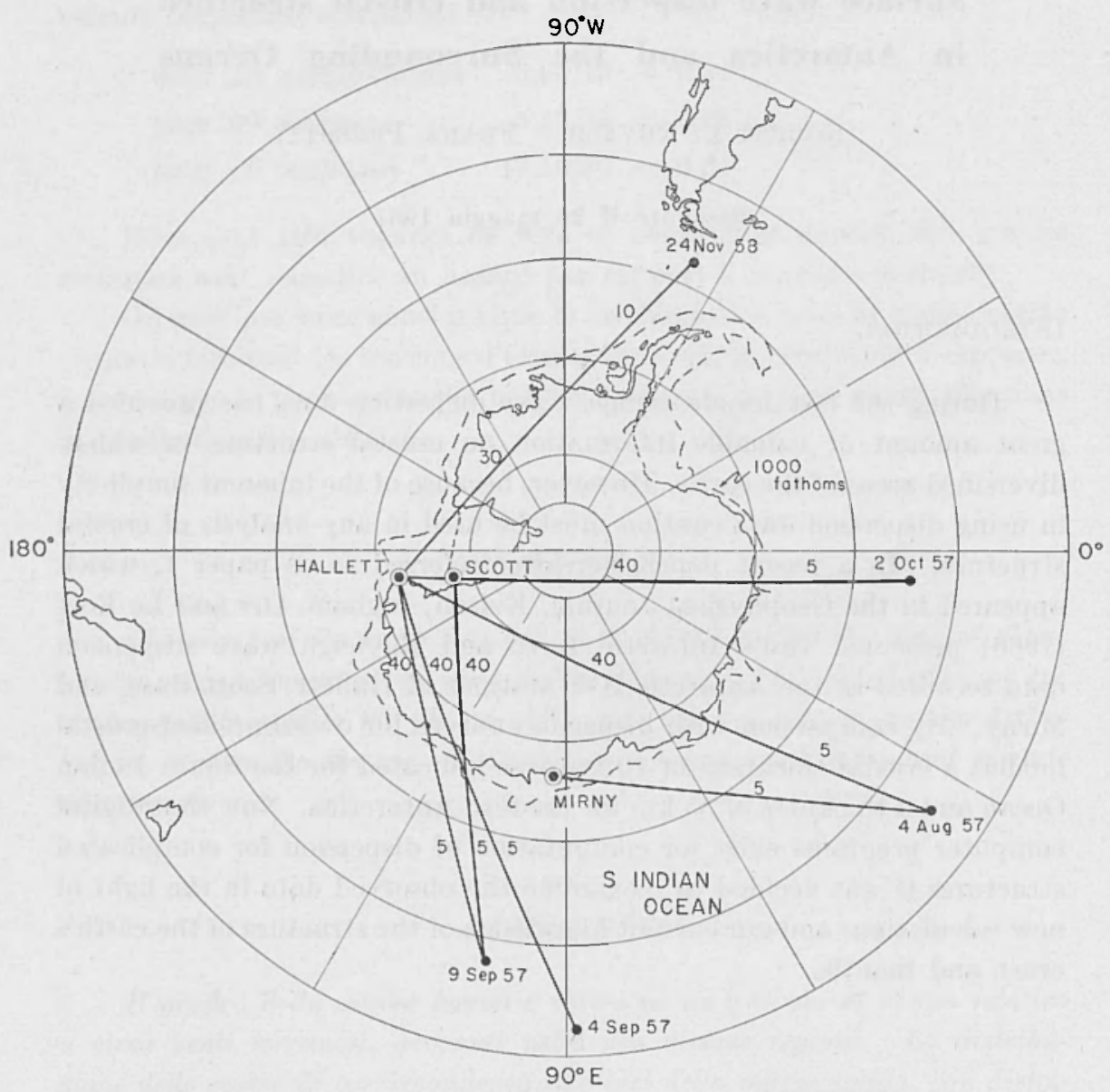

Fig. 1 - Index map showing epicenters, seismograph stations, great circle paths and deduced crustal thicknesses for the Antarctic region.

shown in Figure 2 are composite theoretical curves for a mixed continental and oceanic path. The group velocity of waves of a specific period over the mixed path was computed form the relation $U=(m / U+m / U)^{-}$. where $m$ is the fraction of continental or oceanic path and $U$ is the group 
velocity in the continental or oceanic portion. The theoretical model for Love wave dispersion for both continental and oceanic paths used in paper 1 consisted of one crustal layer overlying a homogeneous

Table 1. - List of earthquakes.

\begin{tabular}{|c|c|c|c|c|c|}
\hline Date & & ter & $\begin{array}{l}\text { Origin time } \\
\text { (GCT) }\end{array}$ & $\begin{array}{l}\text { Recording } \\
\text { Station }\end{array}$ & $\begin{array}{c}\text { Enicentral } \\
\text { Distance } \\
(\mathrm{km})\end{array}$ \\
\hline 4 Aug 57 & $45^{\circ} \quad \mathrm{S}$ & $35^{\circ} \quad \mathrm{E}$ & $21^{\mathrm{h}} 08^{\mathrm{m}} 5 \mathrm{l}^{\mathrm{s}}$ & Hallett & 6537 \\
\hline 4 Aug 57 & $45^{\circ} \quad \mathrm{S}$ & $35^{\circ} \mathrm{E}$ & $\begin{array}{lll}21 & 08 & 51\end{array}$ & Mirny & 4120 \\
\hline 4 Sept 57 & $421 / 2^{0 S}$ & $881 / 2^{\circ} \mathrm{E}$ & $04 \quad 33 \quad 52$ & Hallett & 5294 \\
\hline 9 Sept 57 & $47^{3} / 4^{\circ} \mathrm{S}$ & $101^{\circ} \mathrm{E}$ & $\begin{array}{lll}00 & 13 & 31\end{array}$ & Hallett & 4344 \\
\hline 9 Sept 57 & $47^{3} / 4^{\circ S}$ & $101^{\circ} \mathrm{E}$ & $\begin{array}{lll}00 & 13 & 31\end{array}$ & Scott & 4303 \\
\hline 2 Oct 57 & $54 \frac{1}{1} 2^{\circ S}$ & $5^{\circ} \quad \mathrm{E}$ & $20 \quad 42 \quad 56$ & Hallett & 5891 \\
\hline 24 Nov 58 & $571 / 2^{\circ} \mathrm{S}$ & $651 / 20 \mathrm{WW}$ & $\begin{array}{lll}06 & 48 & 57\end{array}$ & Hallett & 4983 \\
\hline
\end{tabular}

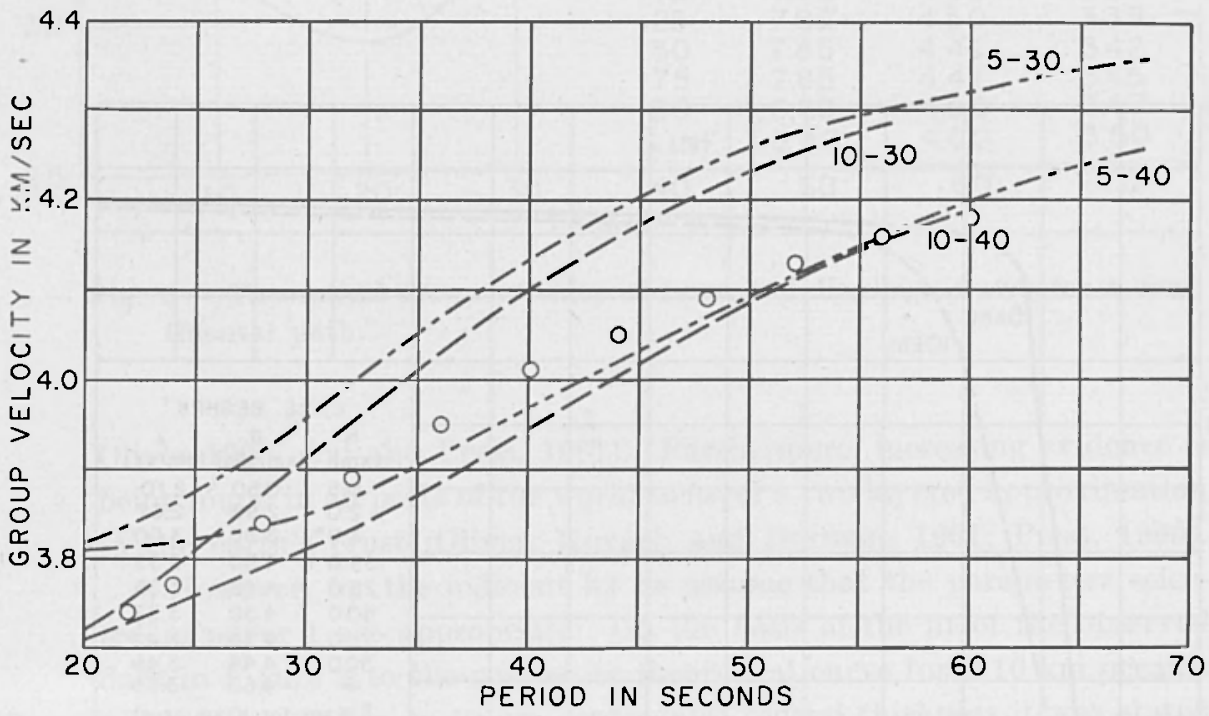

Fig. 2 - Love wave dispersion for shock of 9 Sept. 57 recorded at Hallett shown with Evison's composite theoretical curves for a mixed continental and oceanic path. Note ambiguity in selecting between theoretical curve 5-40 or 10-40 for a 5 or $10 \mathrm{~km}$ oceanic crust. 


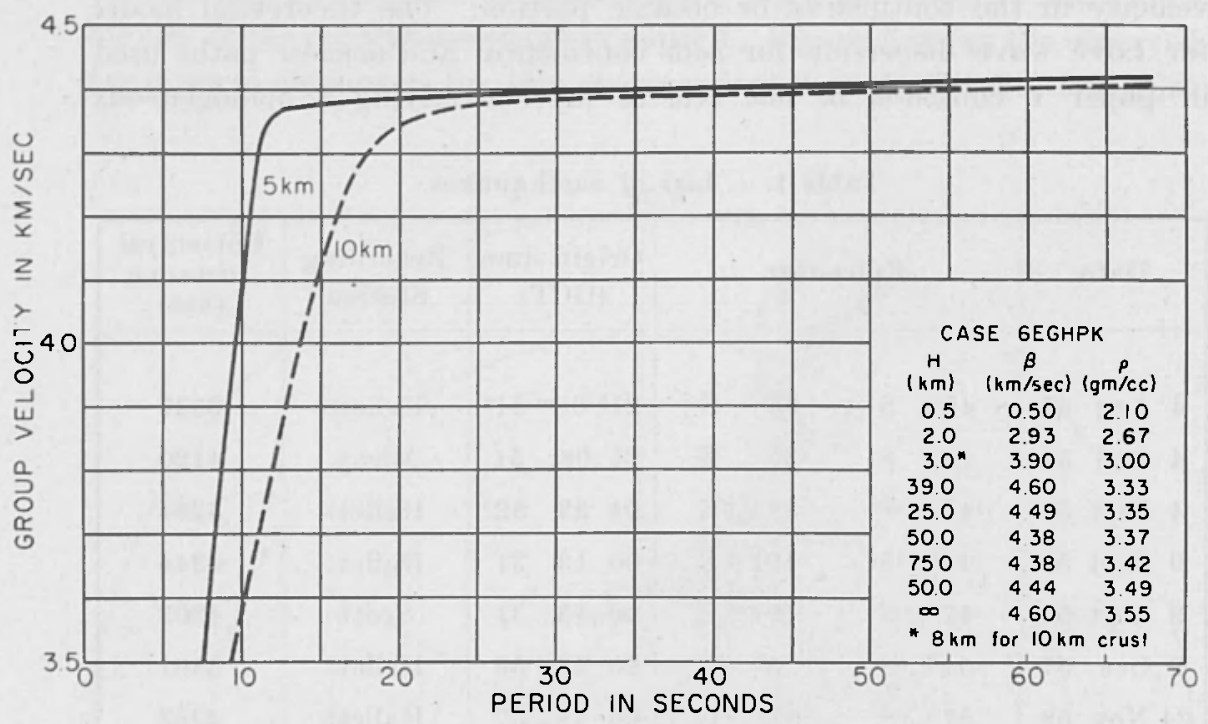

Fig. 3 - Theoretical group velocity of Love waves for an oceanic path.

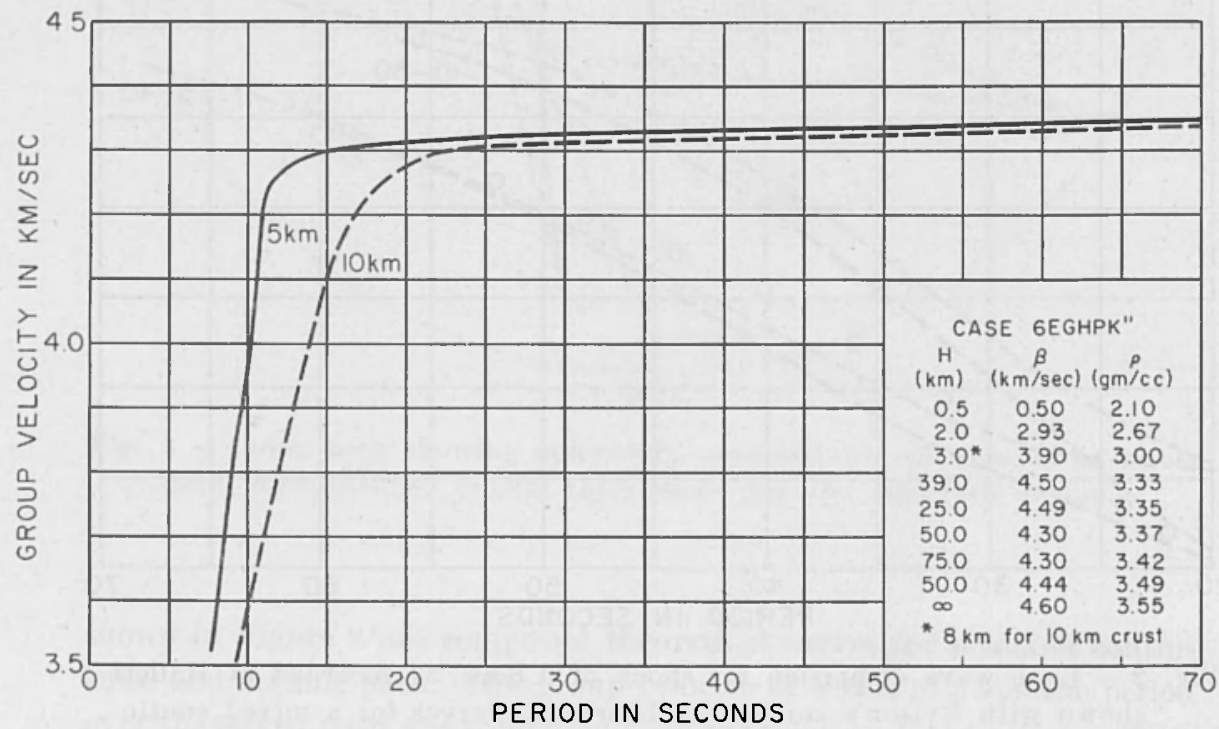

Fig. 4 - Theoretical group velocity of Love waves for an oceanic path. 
semi-infinite mantle. $3.47 \mathrm{~km} / \mathrm{sec}$ was selected for the shear velocity in the crust and $1.5 \mathrm{~km} / \mathrm{sec}$ for the shear velocity in the mantle. These unrealistic values for the velocity parameters are outmoded in view of our current knowledge of the shear velocity distribution in the crust-mantle system and the presence of the low velocity zone in the upper mantle (Gutenberg, 1959; Lehmann, 1955; Dorman, Ewing, and

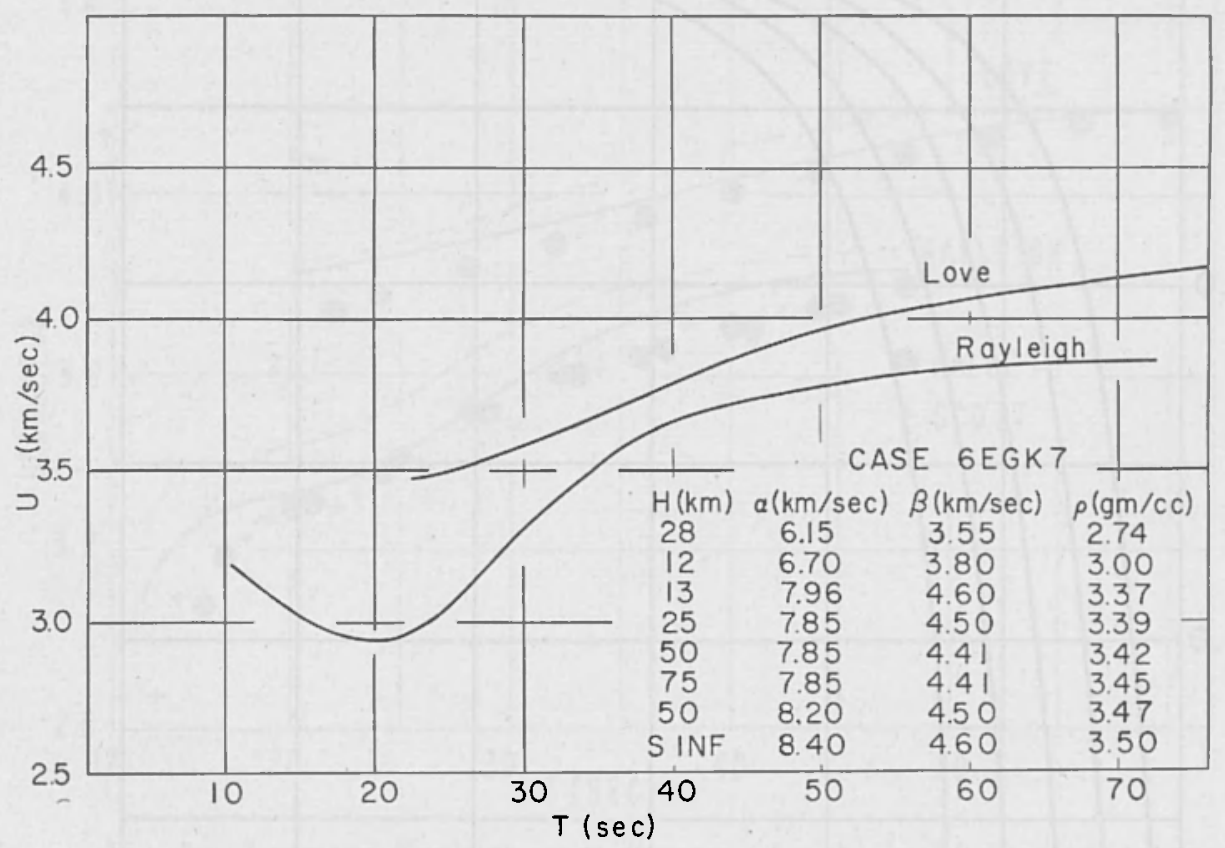

Fig. 5 - Theoretical group velocity of Love and Rayleigh waves for a continental path.

Oliver 1960; Aki and Press, 1961). Furthermore, increasing evidence is being found in all parts of the world to favor a two layered approximation to the earth's crust (Oliver, Kovach and Dorman, 1961; Press, 1960).

However, for the moment let us assume that the parameters selected in paper 1 are appropriate. On the basis of the fit of the observed data in Figure 2 to the composite theoretical curve for a $10 \mathrm{~km}$ oceanic crust and a $30 \mathrm{~km}$ or $40 \mathrm{~km}$ continental crustal thickness it was stated that this indicated a $10 \mathrm{~km}$ oceanic crust in the South Indian Ocean for the particular path studied. We have taken Evison's simplified model and plotted another alternative, namely, the curve for a $5 \mathrm{~km}$ oceanic 
crust. One can readily see that there is little to choose between the two alternatives.

We have used a more realistic oceanic crustal model and calculated on the IBM 7090 digital computer (Press, Harkrider and Seafeldt, 1961)

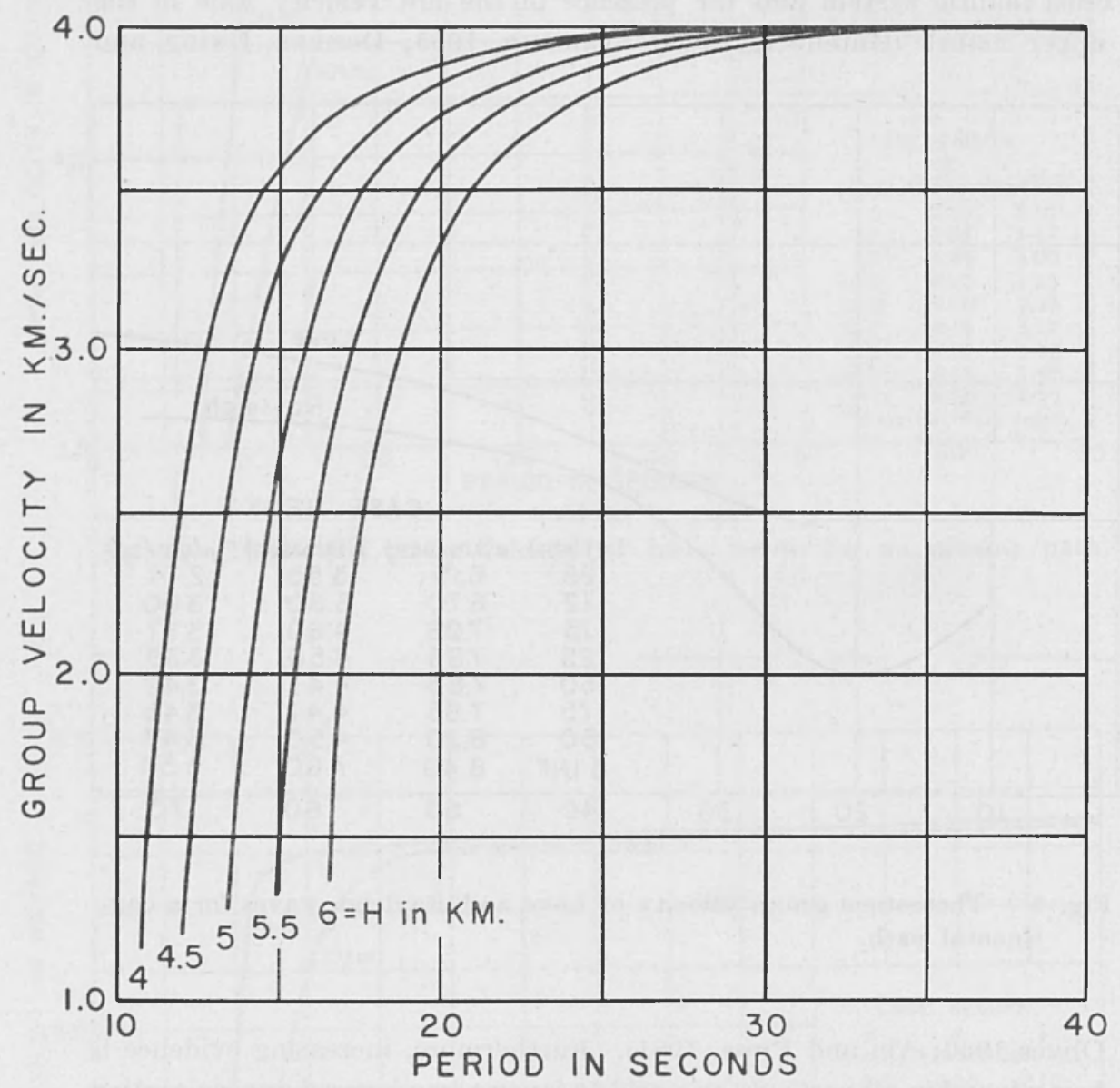

Fig. 6 - Theoretical oceanic Rayleigh wave dispersion curves for Case $6 \mathrm{EGHPK}$.

some theoretical Love wave dispersion curves shown in Figure 3 and 4. The crustal velocities are based on refraction data at sea (Raitt. 1956) and the mantle structure is based on the last results in shear velocity distribution obtained by Gutenberg (1959) from the slope at the inflection points of the S-wave travel time curves for different hypocentral depths. 
In addition. the shear velocity at the low velocity zone has been lowered to take the same value as Dorman's Case 8099 (1960). As shown in Figures 3 and 4 the thickness of the crust is assumed to vary by changing the thickness of the intermediate crustal layer. Now bearing in mind

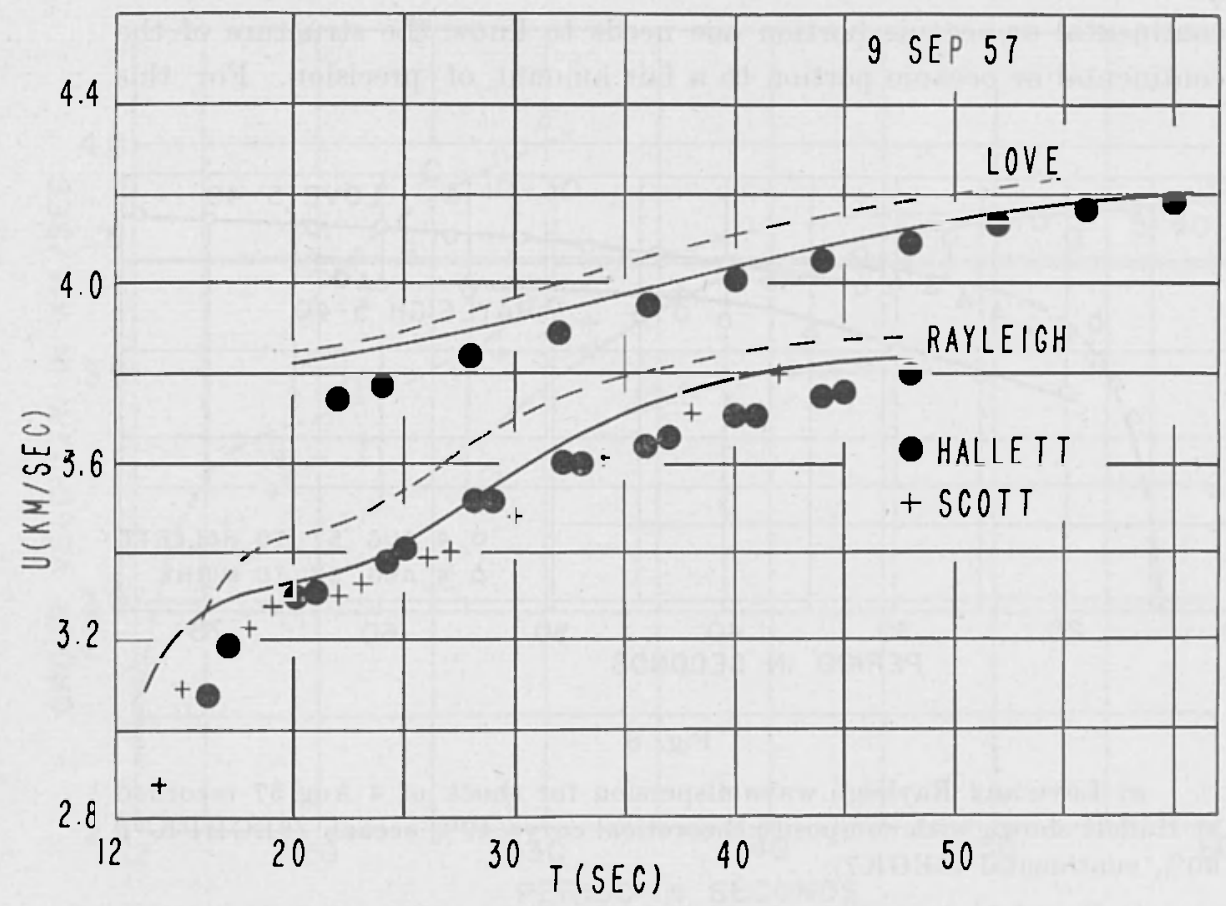

Fig. 7 - Love and Rayleigh wave dispersion for shock of 9 Sept. 57 recorded at Hallett and Scott Base shown with composite theoretical curves for a $50 \%$ oceanic $\left(6 \mathrm{EGHPK}{ }^{\prime \prime}\right)$ and $50 \%$ continental (6EGK7) path. Solid line $5 \mathrm{~km}$ oceanic crust $40 \mathrm{~km}$ continental crust; dashed line $5 \mathrm{~km}$ oceanic crust $35 \mathrm{~km}$ continental crust.

that the observed Love wave dispersion data shown in Figure 2 was in the period range of 22-60 seconds it is interesting to verify from Figure 3 the inability of Love waves for periods greater than about 22 seconds to detect differences in oceanic crustal thickness. However, in paper 1 oceanic Love wave dispersion data in the period range from about 10-24 seconds were presented for a shock in the South Pasific recorded at Scott Base. These short period Love wave data are very strongly influenced by the shear velocity in the unconsolidated ocean bottom sediments, 
which is not well known, so that a precise measurement of oceanic crustal thickness is difficult to make.

For a study of Antarctica the lack of seismicity forces one to use earthquakes with a mixed oceanic and continental path. $\Lambda$ s a consequence, in order to make a statement of crustal structure in either the continental or oceanic portion one needs to know the structure of the continental or ocoanic portion to a fair amount of precision. For this

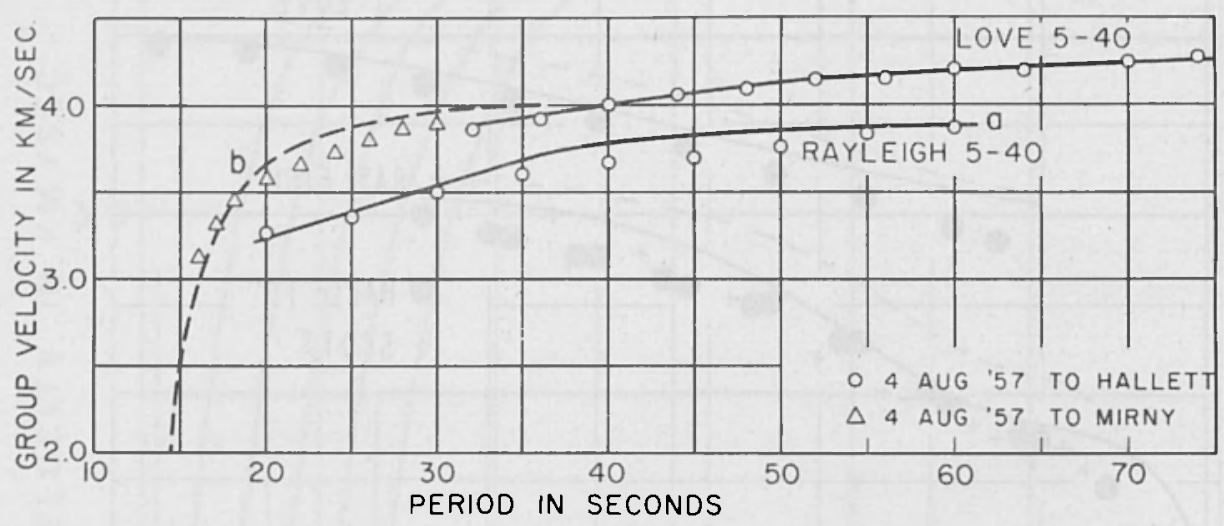

Fig. 8

a) Love and Rayleigh wave dispersion for shock of 4 Aug 57 recorded at Hallett shown with composite theoretical curva $40 \%$ oceanic (6EGHPK"), $60 \%$ continental (6EGK7).

b) Rayleigh wave dispersion for shock of 4 Aug 57 recorded at Mirny with theoretical curve (6EGI1PK').

reason we prefer to select theoretical crustal models compatible with observed earthquake dispersion data for 'average' continental and oceanic paths and compare the observed Antarctic data with these empiricaltheoretical models. For a continental standard we have selected a theoretical model 6EGK 7 compatible with the observed Love and Rayleigh wave dispersion data for a long continental path from the Aleutians to Lwiro in the Belgian Congo (Kovach, 1959). The theoretical dispersion curves for Case 6EGK 7 are shown in Figure 5 and the computed results are tabulated in Figure 10. Case 6EGHPK", (Figure 4) compatible with the previous Indian Ocean data of Kovach and Press (1961), will be used for the theoretical dispersion model across the Indian 
Ocean $(*)$. For surface wave dispersion across non-Indian Ocean oceanic paths we shall use the theoretical curves shown in Figures 3 and 6.

Let us now reinterpret the shock of 9 Sept. 57 (Figure 7 ). Within the limits of our assumed empirical-theoretical model a crustal thickness of

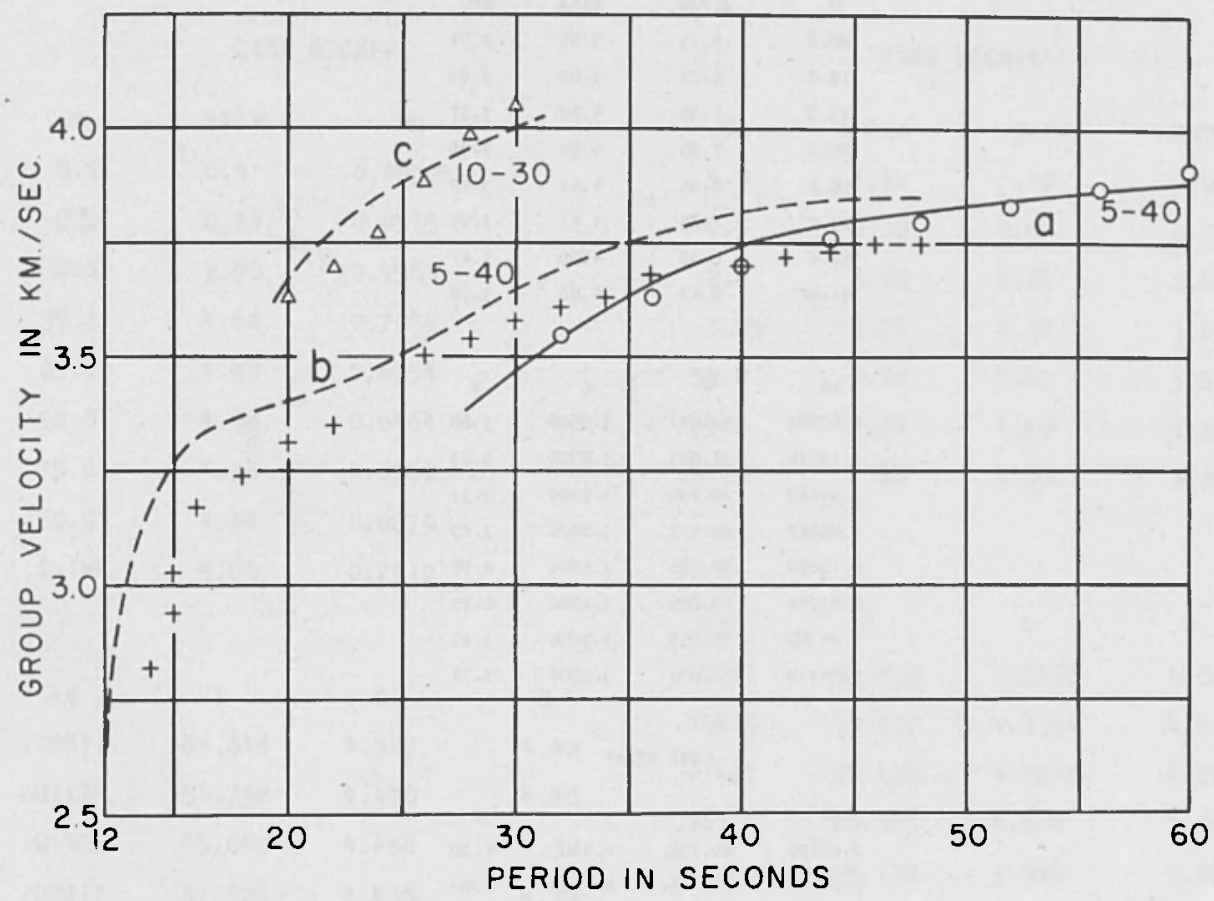

Fig. 9

a) Rayleigh wave dispersion for shock of 2 . Oct 57 recorded at Hallett shown with composite theoretical curve $20 \%$ oceanic (6EGHPK), $72 \%$ continent (6EGK7).

b) Rayleigh wave dispersion for shock of 4 Sept 57 recorded at Hallett with composite theoretical curve $60 \%$ oceanic $(6 \mathrm{EGHPK} "), 40 \%$ continent (6EGK 7).

c) Love wave dispersion for shock of 24 Nov 58. recorded at Hallett with composite theoretical curve $30 \%$ oceanic $\left(6 \mathrm{EGHPK}{ }^{\prime \prime}\right), 70 \%$ continent (6EGK7).

(*) The Rayleigh wave dispersion for Case 6EGHPK" is not presented here. Case 1588 presented in Kovach and Press (1961) gives almost identical dispersion values. 
about $40 \mathrm{~km}$ is indicated for Eastern Antarctica. The composite theoretical curve for a $35 \mathrm{~km}$ continental crust is distinctly inferior. This result is insensitive to the oceanic crustal thickness within the limits $5-10 \mathrm{~km}$.

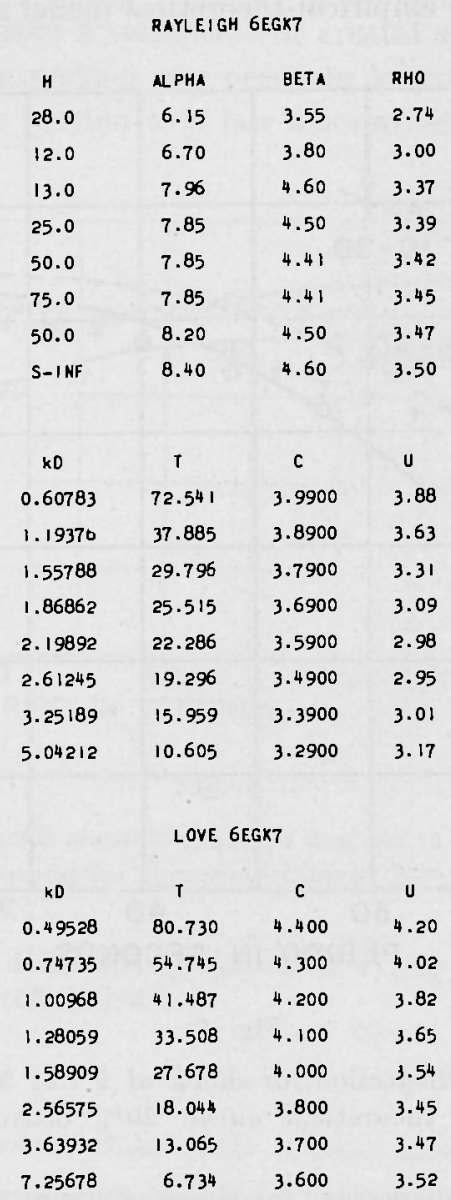

Fig. 10 - Tabulation of dispersion computations for Case 6EGK 7: $\alpha$ and $\beta$ are compressional and shear velocities in $\mathrm{km} / \mathrm{sec}$, $o$ is density in $\mathrm{gm} / \mathrm{cm}^{3}, T$ is period in sec., $C$ and $U$ are phase and group velocity in $\mathrm{km} / \mathrm{sec}, H$ is layer thickness in $\mathrm{km}, k d$ is dimensionless wave number times thickness of top layer.

The analyses for the remaining shocks studied together with the theoretical curves giving the best fit to the observed data are presented in Figures 8 and 9 . The inferred crustal thicknesses in the Antarctic region 
for the great circle paths studied are summarized on the index map in Figure 1. We have not used some of the data presented in paper 1 where the non-Antarctic portion of paths are long and require knowledge of crustal structure over complex regions before an interpretation for Antarctica can be made.

CASE 6EGHPK

\begin{tabular}{cll} 
H & BETA & \multicolumn{1}{c}{ MU } \\
0.5 & 0.5 & 0.00525 \\
2.0 & 2.93 & 0.2515 \\
8.0 & 3.90 & 0.4563 \\
39.0 & 4.60 & 0.7046 \\
25.0 & 4.49 & 0.6754 \\
50.0 & 4.38 & 0.6464 \\
75.0 & 4.38 & 0.6560 \\
50.0 & 4.44 & 0.6879 \\
S-INF & 4.60 & 0.7512
\end{tabular}

\section{CASE 6EGHPK'}

$\begin{array}{cccc}D & \text { ALPHA } & \text { BETA } & \text { RHO } \\ 5.0 & 1.52 & .00 & 1.03 \\ 0.5 & 2.10 & 0.5 & 2.10 \\ 2.0 & 5.09 & 2.93 & 2.67 \\ 3.25 & 6.76 & 3.90 & 3.00 \\ 39.0 & 8.00 & 4.60 & 3.33 \\ 25.0 & 7.84 & 4.49 & 3.35 \\ \text { S-INF } & 7.84 & 4.38 & 3.37\end{array}$

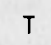

.07887

.19615

.21437

.26170

.31183

.37230

.41376

.50358

.55872

.63846

.74625
98.839

39.807

36.437

29.903

25.192

21.262

19.279

16.280

15.093

14.008

13.182

4.308

3.88

12.661

$$
4.300
$$

Fig. 11 - Tabulation of dispersion computations for Case 6EGHPK and 6EGHPK'. Mu is rigidity in c.g.s. units.

\section{Conclusions:}

As shown in Figure 1 it can be concluded in agreement with Evison that Eastern Antarctica as a whole is continental with a consistent thick- 
ness of about $40 \mathrm{~km}$ being indicated. Since all of the great circle paths studied have a mixed continental and oceanic path our estimate of $40 \mathrm{~km}$ is probably only reliable to within \pm 12 per cent. For the one path studied which crossed Western Antarctica a smaller average crustal thickness of about $30 \mathrm{~km}$ is indicated from meager data.

In contrast to Evison's conclusion we find that a crustal thickness of 5 or $10 \mathrm{~km}$ is consistent with dispersion data for the South Indian Ocean.

In their earlier paper Press and Dewart (1959) concluded that Antarctica was not entirely continental. Five of their surface wave paths crossed East and West Antarctica and their conclusion is thus consistent, with the preceding result which suggests shallow water archipelagic structure for West Antarctica. Two paths crossed the margin of East Antarctica where a thinner crust is probable. One path through the body of East Antarctica is not consistent.

We may better interpret the data of Press and Dewart using the methods of this paper. For comparison of their trans-Antarctic observed Love wave dispersion Press and Dewart selected as a continental standard the observed Love wave dispersion from the Fallon, Nevada shock of 6 July 1954 recorded at Palisades, New York. We now prefer our own empirical-theoretical curve $6 \mathrm{EGK} 7$, where the mean crust is $40 \mathrm{~km}$, as being more representative for continents. When compared to this curve Press and Dewart's Love and Rayleigh wave dispersion data yield a mean thickness of $34 \mathrm{~km}$ for paths across East and West Antarctica. This is thinner than normal, as Press and Dewart concluded. It is still consistent with a normal crust in East Antarctica and a thinner crust in West Antarctica.

This work was supported by grants from the National Science Foundation under their Antarctic Research program.

\section{REFE RENCES}

AKı K. and PRess F., Upper mantle structure under oceans and continents from Rayleigh waves, "Geophys. Journal ", in press, (1961).

Dorman J., EWIng M. and Oliver J., Study of shear velocity distributions in the upper mantle by mantle Rayleigh waves, "Bull. Seis. Soc. Amer.", 50, 87-115, (1960).

Evison F. F., Ingham C. E., ORR R. H. and Le Fort J. H., Thickness of the earth's crust in Antarctica and the surrounding oceans, "Geophys. Journal ", 3, 289-306 (1960). 
Gutenberg B., The asthenosphere low-velocity layer, "Annali di Geofisica ", $12,439-460$ (1959).

Kovacir R. L., Surface wave dispersion for an Asio-African and a Eurasian path, "Jour. Geophys. Research ", 64, 805-814 (1959).

Kovaci R. I. and Press, F., Rayleigh wave dispersion in the eastern Pacific and Indian Oceans, "Geophys. Journal " in press. (1961).

Lenmann I., The times of $P$ and $S$ in Northeastern A merica, "Annali di Geofisica ", 8, 351-370, (1955).

Oliver J., Kovacir R. and Dorman, J., Crustal structure of the' New YorkPennsylvania area. "Jour. Geophys. Research ", 66. 215-225 (1961).

Oliver J. and Iorman J., Nature of oceanic seismic surface waves with predominant periods of of to 8 seconds, reported at the 1961 annual meeting of the Seismological Society of America. (1961).

Press F. and Dewart G., Extent of the Antaretic Continent, "Science", 129, 462-463 (1959).

Press F., Crustal structure in the California-Nevada region. "Jour. Geophys. Research ", 65, 1039-1051, (1960).

Press F., Ilarkrider D. G. and Seafeldt C., Computation of dispersion of surface waves on digital computers. "Bull. Seis. Soc. Amer", in press. (1961).

RaItT R. W., Seismic refraction studies of the Pacific Ocean basin. "Bull. Geol. Soc. Amer", 67, 1623-1640, (1956).

\section{$S U M M A R Y$}

In the light of more recent theoretical calculations on a digital computer the Love and Rayleigh wave data of Evison et al from five earthquakes recorded at Hallett Station, Scott Base and Mirny have been reinterpreted. A mean crustal thickness of $40 \mathrm{~km}$ is indicated for Eastern Antarctica. Less certain is an indication of about $30 \mathrm{~km}$ for Western Antarctica. Evison's determination of $10 \mathrm{~km}$ for the crustal thickness in the South Indian Ocean is unproven because of the inability of Love vave dispersion data for greater than 22 seconds period to distinguish between a $5 \mathrm{~km}$ or a $10 \mathrm{~km}$ oceanic crust.

\section{RIASSUNTO}

Alla luce dei piu recenti calcoli teorici eseguiti su calcolatore, sono stati nuovamente elaborati $i$ dati di Evison ed altri, relativi alle onde di Love e Rayleigh, tratti da cinque terremoti registrati presso le stazioni di 
Hallet, Scott Base e Mirny. Per l'Antartide Orientale si e ottenuto, per lo spessore della crosta, un valore medio di $40 \mathrm{~km}$. Meno attendibile $e$ il valore di circa $30 \mathrm{~km}$, ottenuto per l'Antartide Occidentale. I $10 \mathrm{~km}$ ottenuti da Evison, per lo spessore della crosta dell'Oceano Indiano Meridionale, sono molto improbabili in quanto la dispersione delle onde di Love non consente di apprezzare le variazioni fra i cinque e $i$ dieci $\mathrm{km}$ della crosta oceanica. 